\title{
Should I Stay or Should I Go Now: Wives' Participation in the Decision to Move for their Spouses' Jobs ${ }^{1}$
}

\author{
Elizabeth Ann Whitaker ${ }^{2}$
}

\begin{abstract}
Using a feminist lens, this analysis considers the unequal costs borne by husbands and wives when a family moves for a man's job. The paper, which looks at professional middle-class and upper middle-class families, suggests that there are multiple factors at play to influence a wife's agreement or acquiescence to move including economic concerns and economic rationality, the cultural belief that progress and moving-on are inherently good, a wife's sense of powerlessness in the decision process, and a wife's tendency to perceive her husbands' endeavors as preeminent over others in the household.
\end{abstract}

Key Words: Work/family, job relocation, decision making, feminism, social capital

${ }^{1}$ Special thanks to Dr. Steven J. Gold, Michigan State University, for his input and guidance.

${ }^{2}$ Elizabeth Ann Whitaker, M.A., is a doctoral candidate, Department of Sociology, Michigan State University, East Lansing, MI, 48824. Electronic mail may be sent via the Internet towhitak39@msu.edu

In the United States, there is a national job market for employment, especially professional or managerial employment. When looking for a job or being considered for advancement within a company, individuals are competing with other job seekers nationwide, not just those in the area or within the company. Also, as more and more companies expand and become nationaleven global-possibilities within a company are geographically widespread. More and more people are asked or expected to relocate to other areas of the country in order to take a job, keep a job, or advance in a job. Hodson and Sullivan (2002) pointed out that more than half of all moves in the United States are believed to be work-related and that "promotions, new job responsibilities and even just job retention are sometimes attached to geographic moves" (p. 79). 
This study examined families with heterosexual, married spouses in the professional middle class and upper middle class whose employers have come to regard employee corporate relocation as commonplace and normative. In many cases, for professional middle-class jobs, employers subsidize moves by paying for move expenses and transaction costs associated with home sales and purchases (Worldwide Employee Relocation Council, 2005). Commonly, professional middle-class and upper-middle-class employees are relocated or asked to relocate repeatedly, "sometimes as often as every two or three years and, on average, every five to seven years" (Eby \& Russell, 2000, p. 44).

Hodson et al. (2002) contend that "frequent transfer is a technique firms use to train managers and initiate them into the company" (p. 313). Employers are so interested in maintaining a mobile workforce that they have formed committees, councils, and lobbying organizations that serve to research barriers to relocation; devise strategies to encourage relocation; reduce the attendant costs; and follow legislation that can impact relocation. These initiatives include the Worldwide Employee Relocation Council (ERC); national organizations like the Canadian Relocation Council; statewide organizations, such as the Kentucky Relocation Council; and regional, city-wide, or community-wide organizations like the Chicago Relocation Council.

According to the Worldwide ERC, one trade association for individuals and businesses with an interest in workforce mobility, there are approximately 500,000 corporate-paid employee relocations within the U.S. each year. There is no available data on how many of those 500,000 moves involve children, but estimates say that about 80 percent of relocated employees are married (Eby \& Russell, 2000). Using a conservative estimate of an average of two people being moved in each case, we can calculate that this phenomenon affects at least one million people each year including moved employees, spouses, and their dependent children.

When families are moved to a new community to facilitate a job change for one member of the family, the other members of the family are affected in a variety of ways. There may be some benefits from the move, but there are also costs. An employee's family members must give up their previous home, including the physical dwelling and the surrounding community with its offerings or lack of offerings of arts, activities, stores, scenery, etc. Also, they give up a sense of familiarity, and they give up the close proximity to individuals and organizations with whom they were connected and from whom they drew varying levels of resources such as companionship or support. In some cases, this effect is large. In other cases it is small. And the effect often differs for different members of a family. The cost may be high or low depending on the 
degree to which the community and its accompaniments factored into the family member's life and the degree to which it was currently meeting the family member's needs. A feminist approach to examining the topic reveals the ways in which these costs are highly gendered. It requires one to consider the ways in which place, work, community, and family are gendered and how their gendered nature contributes to the disparate value our society places on them.

In the U.S. we operate under the myth of separate spheres, that is, the myth that work and family are separate and distinct institutions (Garey, 1999; Brush, 1999; Osmond \& Thorne, 1993). Corporations follow this mythical framework in their haste to maximize output and relocate labor to the site where it is deemed to be most expeditious, but the separation is not a real one. In reality there is a significant interconnection between the world of work and the world of family, and no phenomenon exemplifies this overlap as well as the relocation, where the family is physically moved at the behest of the workplace. Even the semantics of relocation, where job-related moves are usually referred to as job opportunities, belie the reality that the move has an effect that reaches far into the reproductive sphere.

By viewing this "work" phenomenon from within the overlapping institution of family and by actively seeking out the gendered aspects, we gain a more thorough understanding of the motivations and requirements behind employee corporate relocation. As stated, I will uncover the role of gender in the interaction between work and family. I will take a feminist approach guided by the themes of feminist theory laid out by Osmond and Thorne (1993). These primary themes implore that one assumes the centrality and value of women's experiences, that one takes gender as an organizing concept in social research, that one questions a unitary notion of "the family," and that one favors methodological approaches that are value-committed to exposing previously disregarded knowledge (Osmond et al., 1993).

Feminist scholars have challenged the separate-spheres ideology over the past two decades, particularly in connection with how it obscures power relations within a family by placing discussions of social stratification in the 'public' realm, the realm thought to be of men, and thereby muting the role of gender in stratification (Osmond et al., 1993). This study follows that tradition by making gender central and by examining the decision process within the family and the marriage that results in a geographic move.

As I indicated earlier, this project focuses on the experiences of professional middle-class and upper-middle class families affected by corporate relocation. Although professional middle- and upper middle-class individuals 
may enjoy privileges in the work arena such as relatively higher levels of autonomy and authority on the job and good compensation compared with working-class and low-income workers, the phenomenon of relocation reveals one of the unique potential difficulties associated with living and maintaining this lifestyle within the industrial West. The individuals who are subject to corporate pressure to forgo place to maintain or improve class status in a corporate world are, in fact, wage earners. Although they often enjoy good salaries and benefits, most are not in the capital-owning class where employment circumstances are irrelevant to their abilities to pay their bills, maintain their lifestyles and provide their families with the things that have become normative in their lives.

In addition, the employment stability of professional middle-class managers has evolved such that the privilege of this group may be more tenuous or short-lived than it once was. Hodson et al. (2002) reported that while managers' unemployment rates have traditionally been very low, the prevalence of organizational change has affected the long-term job-security of managers. Though corporate relocation may only impact a segment of families in the United States, understanding this phenomenon within the current historical context may be relevant for a diverse group of families and for women as they pursue upward mobility. North Americans value upward mobility for themselves and their children, and the possibility and requirements for upward mobility and the different effects of the pursuit of upward mobility by gender are relevant for many.

In this study I looked at the decision to proceed with a job-induced move from the standpoint of the accompanying wife. Existing research supports the contention that work-related family migration is predominantly husband-centered for married couples. Shihadeh (1991) investigated family migration and identified that "the most consistent result is the extent to which wives assumed a subsidiary role in family migration" (p. 441). Zvonkovic, Greaves, Schmiege, and Hall (1996) found that women, even in couples who consider themselves as having similar values and openly expressed opinions, take the secondary position in work-related family decisions. Zvonkovic and colleagues concluded that workrelated family decisions were "more often enacted according to the husbands' preference" (p. 97), although they appeared to be formed through agreement. Bielby and Bielby (1992) also examined the gendered aspects of relocation among dual-earner couples when they considered why women are both less likely to be offered geographic relocations and why they are less likely to accept those they are offered.

By examining this phenomenon from the wife's standpoint, this exploratory study attempted to uncover further knowledge about how this 
significant life change is viewed and negotiated by those who are not at the center of the job relocation yet have a large stake in the outcome of the decision. Through qualitative research among women with dependent children who have been relocated for a husband's job, I explored the ways in which accompanying families viewed a move and attended to its challenges. In this paper, I concentrate specifically on the decision process, that is, how a move is agreed upon given the unequal costs usually being paid by different family members.

\section{Review of Literature}

Several sociological perspectives together inform the understanding of employee corporate relocation and its effects on family. They include feminist theory, studies in work and family, and social capital theory. In each area there has been limited attention to the topic as I have defined it, but what does exist provides a solid foundation for an analysis.

\section{Feminist Theory}

When considering work in the U.S., sociologists refer to productive labor and reproductive labor to express the dichotomy of activities that are perceived to exist for men and women in the middle class. Productive activity, or paid labor, is treated as men's domain while reproductive activity, unpaid labor necessary for the reproduction of everyday life, is treated as women's domain. Brush (1999) stated, “Men's productive activity counts historically and financially. Women's reproductive activity yields, at best, private and non-pecuniary rewards" (p. 161). Even in the increasingly prevalent cases where women work (i.e., they engage in productive activities), they have not been alleviated of their position as primary performer of reproductive activities. Hochschild (1989) revealed in her seminal study The Second Shift how women who work outside the home still do the majority of housework and childcare. Though the production/reproduction dichotomy has not accurately reflected the experiences of many families, especially minority and immigrant families, the perception of this dichotomy as a real one affects the actions of corporations and gender role ideology in the United States.

The dichotomous treatment of productive and reproductive labor results in unequal costs faced by individuals in relocated families. In the industrialized West, when a husband's job results in a physical move for the family, the importance of that productive activity often transcends the importance of other

family members' area-specific activities. Reproductive labor is treated as portable and other family members' productive activities (such as women's and 
children's jobs) are treated as either portable, replaceable or expendable. The gendered nature of productive work and the corresponding advantages bestowed upon it result in disparate power in the decision process.

Past research has considered the gendered nature of decisions about potential relocations and the imbalance of power within the process. Bielby and Bielby (1992) considered the degree to which gender-role ideology "introduces asymmetry into the process by which husbands and wives decide how to respond to a job opportunity in a different location" (p. 1245). Their research, which was confined to dual-earner couples, revealed that gender-role ideology along with labor market structure contribute to a husband's greater power within the dyad. Also, traditional gender-role beliefs within a couple were positively correlated with the decision to decline a wife's relocation opportunity. Shihadeh (1991) examined wives' postmigration employment and found that because females deferred to their partners' employment-related decision to move, they experienced subsequent penalties in their own employment. The finding held regardless of whether the wife held less, equal, or greater human capital and earning power than her partner. In Shihadeh's study, the researcher looked not at the different value placed on productive versus reproductive labor but at the "normative pressures arising out of traditional gender-role distinctions" (p. 442).

\section{Work/Family Studies}

An important subset of family studies within sociology is the area of work and family, where researchers examine not just the overlap between work and family but also the reality that work and family are truly intertwined. Here I am not speaking of particular activities (productive labor and reproductive labor) as discussed above, but of the institutions of work and family. Our society operates under the myth of separate spheres, the belief that work exists within the public domain while family life takes place within the private domain (Baca Zinn, 2000). Family members' activities, then, are viewed as separate from the productive activity that precipitates a move, and it is the family's responsibility to privately reconcile changes that result from a move. The myth of separate spheres between work and family absolves corporations of the need to address and recognize how relocation may infringe on a family. Families must consider the costs and benefits of the prospective move and make a decision. The corporation need only consider how the move affects productivity and the economic goals of the business.

Rosabeth Moss Kanter's (1993) work directly addresses the role of a wife in her husband's professional corporate career. In her study Men and Women of the Corporation, Kanter devoted an entire chapter to the role of a 
corporate wife. One point of view she presented is the wife as victim, constrained by her husband's and the corporation's goals. Kanter discussed the importance of a wife in helping her husband progress in a company through various means, such as projecting an appropriate image and hosting business social events. But the corporate point of view is that anything wives do is voluntary. Corporations do not acknowledge that voluntary behavior takes place "within a system where women are expected to do things out of love, duty, and personal loyalty" (Kanter, 1993, p. 124).

Kanter's work brings the role of the corporation into decisions that affect the family. She debunks the myth of separate spheres demonstrating how the two actually mesh, yet are treated as if they do not. While a family can make its private decision regarding accepting or declining a move, to what degree does the family's response affect the evaluation of a man's commitment to work and the corporation? According to Kanter, women are expected to absorb the goals of the corporation and the degree to which they fill their wifely role is part of the evaluation of their husband. In spite of this, they are considered volunteers, outsiders to the organization, and are offered no credit or acknowledgement for their role in helping their husbands meet the requirements of a job, even when that role involves giving up all familiarity, sense of community, and proximity to friends and family.

\section{Social Capital}

The opportunities and the financial benefits of a corporate move come at a price. That price is the need to undergo a period of social transformation in order to develop new social networks and new support resources. In sociology, we refer to developing new social capital and integrating into a new community. What does this mean for the population being considered here? What resources do they derive from social capital? What is lost by leaving networks behind?

Since social capital is linked to class in myriad ways (Wellman, 1998; Rapp, 1999), we must consider the class position of our population: families who are moved by a corporation to fill a job. Wellman contends that "personal community networks in more prosperous First World milieus are principally relations of reproduction" (1998, p. 237, emphasis original). This is a classspecific generalization that recognizes the higher incidence of economic reliance and sharing or "pooling" among the poor and working classes (Rapp, 1999). In the relocated population under examination here, the middle-class construct holds: Social capital primarily serves needs in the reproductive sphere. In fact, this construct is mandated by the norm assuming the appropriateness of middleclass family self-sufficiency; the norms that discrepancy of condition between 
extended family members and friends is acceptable and that infringing on kin or friends for financial resources or assistance would only be appropriate in dire situations. When exceptional economic resources are called for among the middle class, non-familial institutions are usually called upon in the form of medical insurance, credit, etc. (Rapp, 1999).

Unlike families in less-privileged classes, families in the professional middle-class behave as if networks are not available for financial support and that they ought to maintain economic self-sufficiency at the nuclear family level. "The networks of First Worlders are therefore often built around achieving companionship, soothing domestic stress, and obtaining reliable, flexible lowcost domestic services. These are not trivial pursuits, because few people want to place themselves at the mercy of markets and institutions to deal with such needs" (Wellman, 1998, p. 237). Implicit in the work on class and networks, then, is the fact that forfeiting networks for the population under consideration here equates to forfeiting reproductive resources, the resources drawn upon primarily by women, the stewards of the reproductive sphere. Hansen (2005) argued that middle-class families have increased their reliance on networks to help them rear children and do kin work. The increase, she said, can be explained by the structural changes that have created harsher conditions in middle-class and working class communities, the precariousness of middle class employment, employment insecurity, longer work hours, and a shortage of available kin assistance.

Using the viewpoints above, one would expect a geographic move for a husband's job to result in unequal costs to the partners with the brunt of the costs falling onto the wife. The wife may face losing her paid employment as well as her reproductive labor support. When entering into the decision process to determine whether to proceed with a move, past research and feminist theory shows that wives possess relatively less power as a result of traditional gender ideology and the devaluation of their contributions to the household. As a result of their lower level of power, they may have difficulty translating the potential costs they may have to pay into a factor in the decision process. The research that follows looks at how women in this situation viewed the proposal to move; what processes they engaged in alone and with their spouses to determine how the family would proceed; and what, ultimately, solidified their choice.

\section{Method}

This research is a qualitative, exploratory study that was designed to uncover the meanings that the respondents themselves have constructed regarding their experiences with employee relocation. It is based on eight semi- 
structured, in-depth interviews conducted in 2002 with women who have been moved for their husbands' jobs. Each interview lasted about one and a half to two hours, was tape recorded, and then transcribed. The interviews followed a general interview guide rather than a structured questionnaire and took place comfortably in the respondent's home or a neighborhood coffee house. The qualitative research approach allowed me to see how women viewed the possibility of relocation and to understand what their meanings were in making decisions and moving forward once decisions were made. To find those meanings I sometimes deviated from the general question areas to probe on lines of discussion that were clearly meaningful to the respondents. The nonstandardized format of the interview allowed me to "elicit rich, detailed materials...to find out what kinds of things are happening rather than to determine the frequency of predetermined kinds of things" (Fielding \& Thomas, 2001, p. 125).

In keeping with a feminist approach, I did not adopt a positivistic approach that was intended to uncover objective knowledge. Rather, I have taken the stance that no knowledge is objective and value neutral. Researchers are themselves social actors embedded in the social world with views and experiences of their own, and as a result, complete value-neutrality is impossible to achieve. Feminist researchers have been vocal in proposing a research orientation that is comfortable for both the researcher and the subjects and should discover multiple realities, rather a single Reality with a capital "R" (Berg, 2001). "It tends to involve strategies that listen more and talk less, that humanize the research process and that insist that the...researcher become both involved with his or her subjects and reflexive about his or her own thoughts" (Berg, 2001, p. 140).

Consistent with these feminist research premises, when I recruited and then spoke to my eight respondents I disclosed the fact that I too have gone through the experience of moving on behalf of my husband's job. I believe that this helped to give me and my research some legitimacy in their eyes. Also, I think it contributed to the rapport we had where most interviews took on the form of casual discussions. While I attempted to hear the women's stories and meanings as they reported them, my own experiences may have contributed some biases in the degree to which I probed on certain topics that may have piqued my interests. As Alicea (1997) stated of her research among Puerto Rican migrant women, "It was not possible to separate myself as a scholar from who I am as a ...woman" (p. 603).

Just as my recruitment success was influenced by my position as an insider with this phenomenon, my findings will include some reflexivity on my 
own experiences. Instead of trying to suppress or deny the ways that my own experiences may impact the way I examine this topic, I have chosen to include them alongside the others as additional stories and resources for understanding this phenomenon. Feminist researchers have led the way in adding "the use of personal biography or deep familiarity with a subject" (Berg, 2001, p. 141) to their social research, and I have followed in their path. Including my own three moves, my research will consider 17 separate transfers. (Of eight respondents, two had three moves, two had two moves, and four had one move.)

After gathering the interview data, I examined the transcripts for common themes as well as differences that may explain some of the forces that impacted the decision to make the move. The interviews covered additional topics regarding the move itself and the process of reintegrating into new communities, but for purposes of this paper I will consider only the decision process that took place prior to the move.

\section{Sample}

My intention was to speak only to women who moved with one or more dependent children under age 18 since I believe that the needs in terms of resources and the significance of proximity are different for families with children than they are for singles and married couples. All but one woman met the criterion of moving with children. The exception was Jen (names and identifying information for all respondents have been changed) who did not have children when she made her move but planned on starting a family. Upon arriving in her new community she proceeded under the assumption that her role would be stay-at-home mom, and she was pregnant within a couple of months of her arrival.

Another criterion I had for my sample was to talk only with women who were moved with a corporate-paid relocation. This would ensure that I was looking at the population I intended to look at: families affected by the global nature of the workforce and employers' presupposition of workforce mobility. Again, corporate-paid employee relocation is particularly common among middle managers employed by large firms. Among my eight relocated women, only Tina did not have a fully-financed move. Tina's husband worked as a skilled tradesman, and the corporation only covered expenses for the transportation of the family's goods. Tina and her husband had to pay the transaction costs on the sale of their home and the commuting costs during the family's transition. Although Jen and Tina only fit my requirements loosely, they both added interesting insights to the study. 
I generated the sample using a combination of convenience and snowball sampling techniques. I followed a number of leads to find unacquainted individuals who have been moved for their spouses' jobs. At the time of the research, five of the women lived in the suburbs of the same small Midwestern city, but they lived in various towns and neighborhoods around the area. Many had moved more than once and could speak about the experiences they've had in different geographic locations. All of my subjects were White women between the ages of 30 and 40 .

Limitations. The women I spoke with provided a range of perspectives on the move experience, but there were limitations to the small sample. The age spread of only ten years is small, and the majority of my respondents have dealt only with moves during the earlier stages of their family life course while they had new babies, preschoolers, or early elementary-age children. They all have in the past and continue to reside in suburbs, and the fact that all of the respondents are White leads to the omission of any unique experiences that would involve race. This research could not uncover any such differences, nor did it look at the experiences of families with same-sex parents.

The population of corporate-funded relocated employees is disproportionately White given that "management remains a field with relatively little minority representation" (Hodson et al., 2002, p. 311), but it is not entirely White. According to Hodson and colleagues, "in 2000, only $7.6 \%$ of all executive, managerial and administrative workers were Black and only 5.4\% were Hispanic" (p. 311). Given the low level of representation of minority individuals in this population, the structure of work today, and the White privilege that still exists in the managerial job market, future researchers may find very different results based on varying decision factors for moving and the differential treatment of relocated workers. This project could not discover those potential differences.

\section{Results}

Different corporate relocations can look very different. Some are for jobs within the same company, and others are for positions with new companies. Some arise because the family or the husband pursues them. Others just come up unsolicited. Sometimes a primary bread-winner loses a job and therefore needs a new one. Other times a bread-winner will no longer have a job if a transfer is declined. Some are serial moves. The 17 transfers in this study covered the gamut of circumstances with seven moves for jobs within the same company and ten for jobs with a new organization. Four were directly the result of job loss or threat of eminent job loss. Given all of the different circumstances families face, 
I attempted to find some framework to describe the influences that affected participants' decisions to accept a corporate transfer and, particularly, to see how the wives I spoke with viewed the decision process.

One of the most compelling findings was that most of my informants skipped right over the decision process when they began to tell their stories. In order to find out what took place when the couple determined that they would in fact move, I had to back them up to the beginning. I got the sense that in many cases the wisdom of accepting a move is not really challenged. There was no formal decision process between husband and wife. Instead, there were a series of conversations and emotions that were just somehow foreplay for the inevitable. Most of my respondents didn't really agree to go. They just didn't refuse. For the most part, the women didn't really consider that there should have been a formal process either. Also, although they continually identified how they themselves were concerned or unhappy about moving and their husbands were not, they still viewed the move as consensual.

Zvonkovic et al. (1996) researched the process of family and work decision making among married couples and found similar results. Couples tended to consider their decisions to be made on the basis of consensus, but in actuality, there was contention underlying the consensus. The surface explanation of consensus contrasted with the data that showed a majority of couples differed in what they wanted to happen and "the decision enacted more often reflected what the husband wanted to happen" (p. 96). The authors contended that the outcome of work decisions seemed to be formed through a process identified by Kompter (1989) as "apparent consensus," occurring among couples who believe they are in agreement about an issue and who believe that this agreement reflects mere commonsense, when, in fact, their beliefs are based on male power and privilege" (Zvonkovic et al., 1996, p. 97).

The stories of my respondents resonate with Zvonkovic and colleagues' findings. The women described situations where both spouses were in agreement, where discussion and empathy were present, yet except in one case there was no point where the wife gave her ultimate approval of the choice to proceed with a move. There was a sense of "going along with it" and that doing so was commonsense in spite of the wife's own lamentations. For example, two of my respondents characterized the decision situation with the comments "I didn't resist" and "I didn't fight it." When Eileen relayed her experience it was clear that she was especially tormented about her first move, an optional transfer to facilitate a promotion. She shared her distress and emotions with her husband; although he listened and sympathized, they continued to proceed with the move 
since she never summarily refused. I asked her if there was ever a time when she considered not taking the move and she said,

For me definitely but not for him. We talked about it a lot...I pretty much just had to resolve it for myself. My husband was very understanding for a while.

When talking about their next move, I asked if this time the two agreed on what to do. Eileen laughed when she said,

I don't know if we agreed...As I heard before, "It's the right thing to do Eileen, the right thing to do."

Eileen appreciated her husband's "understanding" even though that understanding did not include considering her position. She saw her own view as something that should be tolerated and understood, rather than factored in as a viable possibility. In her second move she again deferred to what her husband wanted to do.

When I looked more closely at the decisions from the wives' points of view, I saw that there were multiple factors that led to the high degree of acquiescence. The four I list first are the positive influences, that is, the factors that pointed toward accepting, or more accurately, "going along with" a transfer. These four positive influences were a) structural concerns/economic rationality, b) restlessness, c) powerlessness, and d) the preeminence of the husband's endeavors.

\section{Structural Concerns/Economic Rationality}

Findings from this research demonstrate that decisions to accept employee corporate relocation are not exclusively the result of micro-level politics within the home. Macro-structural realties contribute to many, if not all, relocations in some capacity. The state of the economy, the company and the job market come into play. For example, one move was the result of a corporate takeover that threatened to eliminate the husband's job as redundant, one was the result of a threatened downsizing, and one was the result of a job lost to corporate takeover and reorganization.

Yet another structural consideration came into play for Cindy, a stay-athome mom and former attorney who moved two states away when her husband, who was doing well as a self-employed marketing consultant, took a job with a

large corporation. These two were the only couple who very formally engaged in 
a methodical decision process that included a list of pros and cons. In the end, the deciding factor in accepting the position was its inclusion of health insurance. In the U.S. today, independent policy holders can be dropped from their health insurance if they have a serious illness, and this had been concerning Cindy and her husband for some time. The way that the U.S. healthcare system is structured, with payment for healthcare coming primarily from insurers and access to insurance being linked to employment, affected Cindy's family's life choices.

The above examples demonstrate direct structural influences: cases where there was a specific and known economic factor driving the choice. Some moves that are not the result of direct structural influences are still structurally motivated - albeit in an indirect or invisible way - by the overarching sense of insecurity many workers feel today. These would include cases where relocation or even willingness to consider relocation is affected by an employee's desire to stay one step ahead of reorganizations or to make oneself known to be loyal or indispensable should a reorganization or downsizing come along.

The re-engineering of work in the 1990s has created an environment that researcher Sarah Ryan (1999) called "management by stress." She listed "corporate mergers and reorganization with workforce downsizing" (p. 335) as one of seven major aspects of work re-engineering today. She pointed out that "while manufacturing jobs have typically been thought of as most vulnerable to layoffs... white collar work was as insecure in the 1990s" (Ryan, 1999, p. 335) When families partner the insecure nature of managerial work today with the belief in the need to maintain economic self-sufficiency within the nuclear family, middle-class families are reminded that they are wage laborers. In cases where the family's livelihood is potentially at stake, wives' acquiescence is often based on economic rationality.

Allison's family moved for the fourth time shortly after our interview. We got together to discuss the circumstances surrounding this change, which clearly exemplified a situation where fear of a potential corporate restructuring acted as the impetus for moving. She explained that her husband was doing well in his company heading up an entire plant. However, the precarious nature of the industry in which he works made them concerned that there would be plant closings in the future. Allison's husband believed that his small plant was vulnerable. He heard about a position at one of the company's larger operations and pursued it in order to be preemptive, although he would no longer be in charge of his own facility. 


\section{Restlessness/opportunity}

The second positive influence speaks to James Jasper's (2000) idea of "restlessness" in U.S. culture, both currently and historically. This restlessness, as Jasper termed it, began at the genesis of our country and with its role as the "land of opportunity," the place for people to go for a better life. Our society was formed by immigrants, those who moved to seek a better life. Our history and the glorification of the stories of the past, our tight grip on our image of the United States as a place where anyone can make it, have lead to our underlying beliefs in both the importance of social mobility and the glamour of physical mobility as a means to it.

There is a general sentiment that opportunity is good and that moving on is desirable. Jasper explained that "Americans have come to believe that migration and starting over are normal" (Jasper, 2000, p. 11), which implies that not doing so is abnormal. There is a cultural norm telling us that it is unnatural or irrational to resist "progress." This sentiment plays a supporting role for many people, even those who want to resist. I am including here the outlook that material advancement for the family is valued even above social connectedness, stability, and place identity.

Tina's comments show that she subscribes to the notion of moving on as being a good thing. Tina said that her marriage had been "getting bad" and her slightly overweight daughter was having some difficulty at school. She explained,

\section{I didn't resist. If it had been another time in my life I probably} would have resisted. I looked at it as just a new start.

Tina was bringing her husband and her daughter's weight problem with her, yet moving and starting over seemed to be a possible answer. Tina's move was precipitated by the threat of a downsizing but, rather than dwell on the structural coercion, she preferred to see the opportunity as a "new start." She was very unhappy with the prospect of moving and she engaged in an internal process of justification and rationalization to come to terms with it. Through this internal process she called upon our societal norm that suggests moving on is desirable, sensible, and even exciting to help herself to become reconciled with the situation. At no time did she and her husband come to this conclusion together or share the idea with one another.

Rebecca spoke as if moving on was intrinsically desirable. She was not rationalizing as much as embracing the norm when she said, 
Well, I think that's why I was so open to moving to [the Midwest], because I hadn't been anywhere else. I was born in Oregon, lived in Oregon, went to school in Oregon, stayed in Oregon, all my friends were in Oregon.

The other two positive influences I identified speak very much to gender; they both were overwhelmingly present among my respondents, and they often went hand in hand.

\section{Powerlessness}

The women in my sample expressed a sense of powerlessness regarding the decision, but that powerlessness was self-imposed rather than being the result of an authoritative husband. Perhaps more accurately, the powerlessness was culturally or structurally imposed by the gender-role ideology discussed earlier. Powerless women internalized the viewpoint that their role in the family, in the reproductive realm, is subordinate to their husband's role in the working world, in the productive realm. Even in dual-earner families, gender-role ideology created a belief that the husband's position as primary earner was sacrosanct. The stories I heard were not those of men who came home and necessarily demanded that their families pick-up and go, but rather stories of women who didn't believe that they deserved a vote. As Jen put it, "I guess I also didn't really think I did have a right to refuse."

\section{Preeminence of Husband's Productive Endeavors}

There was an almost universal sentiment among the wives that their husbands' career advancement is so important that it supercedes other considerations. I am not talking here about the desirability of economic advancement for the family, but the preeminence of the husband's endeavors over other family members' endeavors. Four of the eight informants gave up their own paid labor as a result of a move. Marie's experience is a good example. Her husband took a faculty position at a university that required they move across state lines. At the time, Marie was a practicing attorney. She said,

To get any sort of reciprocity, where you don't have to take the next state's bar exam you had to be licensed for five years. So I missed it by a year. Which I was not happy about, but there was no way he wanted to sit and spin his wheels for another year. 


\section{Discussion}

Most of the informants' testimonies showed that more than one of these four influences was at play in the decision process. Powerlessness revealed itself in almost half of the move cases. In every case where the wife was fully against the move, she expressed a feeling of powerlessness. One of the influences that led her to go along with the move was her sense that she did not have the power or the right to resist. The sources of that powerlessness included economic concerns, the sense that she had no right to challenge or stand in the way of her spouse's opportunity, or the feeling that her spouse was financially supporting her chosen field of motherhood so she had somehow relinquished her right to a vote.

When I talked with Eileen about her husband's promotion to a job five hours away, she summed up a combination of two influences that affected her thinking - her own powerlessness considering the importance of her husband's aspirations:

At this time I was a stay-at-home mom and the guilt was overwhelming. What exactly did I have to stay in [city] for? Just pretty much because I didn't want to be away from friends and family was the only reason. It was my husband's career, and I didn't have a career then other than being a full time mom.... Ultimately this is his career and if I was going to follow him up the corporate ladder then this was what we had to do.

I previously mentioned Jen. Her comments showed that all four of the different influences played into her feelings about a move that her husband was offered after his company entered into a merger and his job was at risk. In spite of all of her feelings, ultimately she didn't really contribute to the decision:

He was used to going where ever his career took him...To hear him say it, he would say that even if we weren't going through the merger, if he had become privy to the knowledge about this job, he would have wanted to take it merger or no merger. And I would probably have fought kicking and screaming if he didn't have any real reason to change jobs....I think I got caught up in the "Wow." It was scary but kind of like exciting. I had moved when I went to [college]. It was only five hours away I know, but I went there not knowing a soul. I'd kind of broken away. Some people go their whole lives and never really leave their sense of security as far as their home town. I had done it and created this 
wonderful life for myself...So I was a little braver because of that. Anyhow, I don't know. I guess I also didn't really think I did have a right to refuse.

Movers also may experience some negative influences on the decision process; that is, things that make them want to stay put. Obviously because I spoke only with movers, these influences did not win out. I looked at what was common among movers, so it may be that some potential movers do weigh these negative influences and thus decline their transfers. All that I could determine in this study was what negative influences there seemed to be for movers.

In my research I heard about these factors when women described reasons they didn't really want to move or things they, themselves, would miss. None of the women other than Cindy (who was the only one to create a formal $\operatorname{pros} /$ cons list) included these factors into the decision process. Although they were discussed as part of the lamentations to the move, they never held any weight. The women recognized these as losses and problems and sometimes their husbands agreed that these were truly unfortunate casualties to the move. Based on my informants, movers recognized the following as losses:

1. Loss of place. In terms of place, people can have ties to the areas' amenities or they can have place identity, a feeling of history or belonging that stands apart from objective measures of the area

2. Loss of friendships. Some friendships will persist long distance. Others will fade away. But the character of friendships from the original community will change upon leaving

3. Loss of family ties. Again, family will continue to be family, but the character of family relationships and the opportunities for interaction will change if movers are leaving family behind.

The three factors - place, friendship ties and family ties - relate to our mythical private realm of life. In reality, these are resources that often provide substantial benefit to families' daily functioning and well being rather than separate and distinct from productive activities. As I heard the women discuss these as losses, yet not as viable factors for declining moves, it was evident that the public/male-associated realm was seen as more valuable and legitimate than the private/female-associated realm. Couples distinguished these realms in their discussions and their decision process, not recognizing the fallacy of the dichotomy between the two. Here are some of Jen's thoughts that demonstrate what she would be leaving behind: 
I really loved where we lived. It was a perfect fit. It wasn't right on top of my family but close enough to see them. And the town, they'd just made so many great improvements. It is just a great place to live and I hated to leave. To leave the town, our friends. Jim and I, that was like our little family.

But these thoughts never factored into Jen's family's decision. Cindy had similar thoughts, especially about the area. She said "It's just so beautiful here, and I know where everything is. And Holly was born here."

\section{Conclusion}

Although this research is based on a small number of interviews, it suggests some strong gender-related dynamics involved in the decision process associated with a couples' determination to relocate for a husband's job. Our precarious and transitioning economy either directly or indirectly played a role in wives' and couples' beliefs that they should not close the window on opportunities to remain employed, to advance in a company, and to demonstrate loyalty and commitment to a company. Macro-economic concerns and "management by stress" factored in significantly.

In arriving at these decisions there was an underlying power imbalance between husbands and wives that appears to be the product of the production/reproduction dichotomy in the U.S. More specifically, it is derived from the traditionally unequal value placed on the primary spheres perceived to be associated with each gender and on traditional gender-role ideology. Also, women had a sense of powerlessness and/or internalized the belief that their husband's endeavors are more important than their own.

Wives subscribed, to some degree, to the sentiment that moving on has positive connotations, and even in cases where they didn't personally subscribe to this sentiment, they considered their own feelings as irrational, bad attitudes, or a tendency to be inflexible. Somehow their unwillingness to go was perceived as a flaw in themselves, so they suppressed it or rationalized it away.

The power imbalance was also demonstrated by the character of the interactions that lead to the final acceptance of the new position. In all but one case, the couple did not really come together to decide. Rather, women were caught in a tide of something that was happening with the unspoken understanding that if they wanted to stop the course they were on, they would have to step forward with a refusal. Partners did discuss the move with their 
wives but less as a means to actually figuring out what to do-take the job or don't take it — and more as a working through of issues and concerns.

Employee corporate relocation is part of our society today, and corporations and entire industries have a vested interest in maintaining a mobile workforce. I think it is important to examine this topic and find ways that our culture either positively or adversely affects families that experience relocation. This research serves as an exploratory first step in identifying the process and influences that lead to decisions to relocate.

In future research it may be beneficial to include wives whose families have declined relocations, relocated wives in various stages of the life course, and relocated non-White wives. Also, research with couples would allow us to discover the differences in how men and women in relocated families perceive the process and the influences. Comparative analysis based on these variables may further develop and refine our understanding of the decision process. 


\section{References}

Alicea, M. (1997). A chambered nautilus: The contradictory nature of women's role in the social construction of a transnational community. Gender \& Society, 11(5), 597626.

Arnett, S. (2002, August). Formations of identity and meanings of home: Psychological and cultural perspectives. Paper presented at the annual conference of the American Sociological Association, Chicago, IL.

Baca-Zinn, M. (2000). Feminism and family for a new century, The Annals of the American Academy, 571, 42-56.

Berg, B. L. Qualitative research methods for the social sciences. Boston, MA: Allyn \& Bacon.

Bielby, W. T., \& Bielby, D. D. (1992). I will follow him: Family ties, gender-role beliefs and reluctance to relocate for a better job. American Journal of Sociology, 97(5), 1241-1267.

Brush, L. D. (1999). Gender, work, who cares: Production, reproduction, deindustrialization, and business as usual. In M. M. Ferree, J. Lorber \& B. B. Hess (Eds.), Revisioning Gender (pp. 161-189). New York: Sage.

Cuba, L., \& Hummon, D. M. (1993). Constructing a sense of home: Place identity and migration across the life cycle. Sociological Forum, 8, 547-572.

Eby, L. T., \& Russell, J. E. (2000). Predictors of employee willingness to relocate for the firm. Journal of Vocational Behavior, 57, 42-61.

Fielding, N., \& Thomas, H. (2001). Qualitative interviewing. In N. Gilbert (Ed.), Researching social life (pp. 123-144). London: Sage.

Hansen, K. H. (2005). Not-so-nuclear families: Class, gender and networks of care. New Brunswick, NJ: Rutgers University Press.

Hochschild, A. R. (1989). The second shift: Working parents and the revolution at home. New York: Viking.

Hodson, R., \& Sullivan, T. (2002). The social organization of work. Belmont, CA: Wadsworth.

Hood, J. C. (1983). Becoming a two-job family. New York: Praeger.

Jasper, J. M. (2000). Restless nation. Chicago: University of Chicago Press. 
Kanter, R. M. (1993). Men and women of the corporation. New York: Basic.

Kompter, A. (1989). Hidden power in marriage. Gender \& Society, 3, 187-216.

Portes, A. (1998). Social capital: Its origins and implications for modern sociology. Annual Review of Sociology, 24, 1-24.

Putnam, R. D. ( 2000). Bowling alone. New York: Simon and Schuster.

Rapp, R. (1999). Family and class in contemporary America: Notes toward an understanding of ideology. In S. Coontz (Ed.), American families: A multicultural reader (pp.180-196). New York: Routledge.

Ryan, S. (1999). Management by stress: The reorganization of work hits home in the 1990s. In S. Coontz (Ed.), American families: A multicultural reader_(pp 332-341). New York: Routledge.

Ryle, R. R., \& Robinson, R. V. (2002, August). A place to belong? Sources of community and belonging in the United States. Paper presented at the annual conference of the American Sociological Association, Chicago, IL.

Shihadeh, E. S. (1994). "The prevalence of husband-centered migration: employment consequences for married mothers. Journal of Marriage and the Family, 53(2), 432444.

Wellman, B. (1998). The place of kinfolk in personal community networks. In K. V. Hansen \& A. I. Garey (Eds.), Families in the U.S.: Kinship and domestic policies (pp. 231-239). Philadelphia: Temple University Press.

Worldwide Employee Relocation Council (2005). Retrieved August 17, 2005 from http://www.erc.org

Wuthnow, R. (1998). Loose connections: Joining together in America's fragmented communities. Cambridge, MA: Harvard University Press.

Zvonkovic, A. M, Greaves, K. M., Schmiege, C. J., \& Hall, L. D. (1996). The marital construction of gender through work and family decisions: A qualitative analysis. Journal of Marriage and the Family, 58(2), 91-100. 